\title{
Manual accidents, biological risk control, and quality indicators at a children's hospital in north-east Italy
}

This article was published in the following Dove Press journal:

Risk Management and Healthcare Policy

13 April 2015

Number of times this article has been viewed

\section{Sergio Parco \\ Fulvia Vascotto \\ Roberto Simeone \\ Patrizia Visconti}

Department of Health Technology Assessment, Institute for Maternal and Child Health, Trieste, Italy

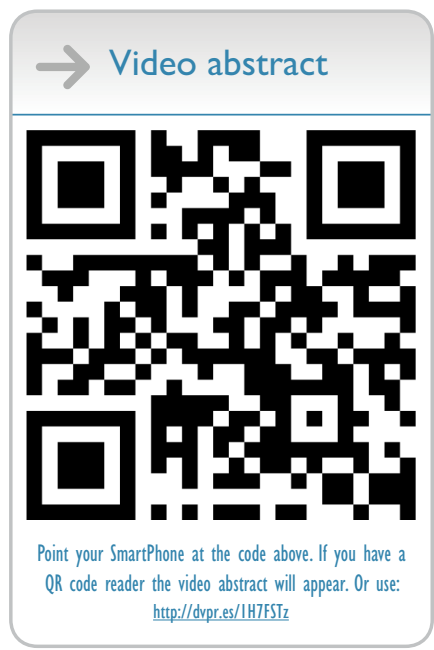

Correspondence: Sergio Parco Institute for Maternal and Child Health, Via dell'Istria 65/I, Trieste, Italy

Tel +390403785332

Email parco@burlo.trieste.it
Background: Working in health care carries the risk of transmission of infected blood to patients by hospital workers and to other health personnel in the form of occupational infections. Conscientious application of the standard precautions is the main method used to avoid needle stick injuries, contamination of skin and mucous membranes, cuts with sharp tools, and inadequate disposal and recapping of needles. The aim of this work was to investigate in Friuli Venezia Giulia, a region in north-east Italy, the enhancement carried out to prevent situations of biologic risk for health care workers, and to verify the related laboratory analyses.

Methods: Biological accidents occurring during the years 2012-2013 in the departments of oncology and pediatric-obstetric surgery, and in the intensive care unit at Burlo Garofolo Children's Hospital in Trieste (a large town in Friuli Venezia Giulia) were reviewed, and a new panel of tests was introduced for patients and health care workers, to also detect human immunodeficiency virus (HIV), hepatitis C virus (HCV), hepatitis B virus (HBV), and aspartate transaminase and immunoglobulin G. All tests were submitted for external quality assessment.

Results: In total, 230 nosocomial events were reported by health care workers in the abovementioned hospital departments in 2012-2013. There were 158 accidents in 2012, including 55 accidental needle stick injuries (34.81\%), 59 blood splashes (37.34\%), and 44 cuts with infected instruments $(27.84 \%)$. The risk of sustaining a cut was related to movement error during surgery when the appropriate procedure was not followed or when devices were being assembled and passed between doctors and nurses. Most accidents happened among physicians compared to nurses; the high percentage of needle stick injuries (34.81\%) versus nurses (25.94\%) were due to incorrect recapping of needles after use. No cases of health care workers being infected with HCV, HBV, or HIV were identified. In 2013, the number of biological accidents decreased to 61 , comprising two needle stick injuries (3.27\%), 35 blood splashes (57.37\%), and 25 cuts with contaminated instruments (40.98\%). The number of subcutaneous abscesses with scarring resulting from cuts with sharp instruments decreased from three in 2012 (one of which was the subject of medicolegal proceedings) to none in 2013. Although our study population was relatively small, we did detect a statistically significant decrease in the number of needle stick injuries $\left(P<0.05, \chi^{2}\right.$ test $)$.

Conclusion: In this early experience at a maternal and child health institution in the Friuli Venezia Giulia region, application of a safety protocol, centralized organization of HIV tests, improved external quality assessment, and introduction of internal quality control for immunoglobulin $\mathrm{G}$ contributed to a decrease in the number of work-related biological accidents and their complications, which have the potential to result in medicolegal problems.

Keywords: manual accidents, health care workers, intensive care 


\section{Introduction}

Although there are some data in the literature on control of biological risk in some European Union (EU) countries, including Portugal, England, and Switzerland, there have been no relevant studies reported for Italy, because the Eurosurveillance program of occupational exposure to blood-borne pathogens is a work in progress. Health care workers are at particularly high risk, being exposed on a daily basis to human blood, urine, and feces, as well as accidents connected with medical and surgical procedures. The risk of sharps injuries and becoming infected via contaminated blood is often associated with inadequate use of devices for personal protection. Health and sanitation workers are at risk of occupational infections, particularly those that can be transmitted by blood from hospitalized patients. Scrupulous application of the standard precautions is the principal method used to avoid punctures when recapping needles, tears or occult perforation of gloves, cuts with sharp tools, and cutaneous and mucosal contamination. ${ }^{1-5}$ When a hospital employee acquires an infection by accident the procedure of clinical risk demands the description of the measures both the hospital and the worker made to prevent it; the negligence, actually, is no more legally admissible. ${ }^{6-8}$ Further, the relevant legislation varies from country to country and, in some cases, the results are based on the specific wording and interpretation given by the court in each state. ${ }^{9-15}$

The EU regulations regarding the prevention of cuts and puncture wounds and related contamination in the health care sector are applicable to all health care personnel. In the Friuli Venezia Giulia (FVG) region in north-east Italy, health and safety protocols are applied not only in all hospitals but also in hospices and home care: the vaccination programs for hepatitis B virus (HBV) and the security rule for human immunodeficiency virus (HIV) and hepatitis $\mathrm{C}$ virus (HCV) infection are not yet mandatory, in all the public and private sanitary, medical, and charitable facilities. The Ministry of Health in Italy has issued, for both patients and workers with suspected HIV infection. Guidelines for clinical use of antiretroviral therapies, with references to doses, time and execution of the care, and the related analyses. ${ }^{16-20} \mathrm{In}$ accordance with EU legislation and Italian regulations, our institution, a maternal and child health hospital in Trieste, north-east Italy, holds regular meetings and courses to update physicians, nurses, and allied health and sanitary personnel on procedures to follow in the event of a biological accident, with the aims to decrease the risk of such events for health care workers and patients, to investigate the nature of the accidents that do occur, and to assist in the development of procedures for infection control in hospitals in north-east Italy.

Blood contamination may be high risk if there has been direct contact with virus in the laboratory, or via a deep injury with bleeding; of middle risk from contact with contaminated medical instruments and infectious blood, skin exhibition, or conjunctiva injured with biological liquids; of low risk in cases of contact with a superficial injury without bleeding, or bites and injuries during the phase of healing. There is also an increased risk in cases of contamination of the entire skin - visually proved, or not visually proved (minimal blood contamination), in the presence of factors that increase the level of risk, such as deep injuries and compressions. The same applies for patients at the last stage of acquired immune deficiency syndrome or in some subjects without expression of surface antibodies, during the so-called "window period".

For hazardous transport there are rules to avoid contamination of health care workers during delivery of biological samples to the laboratory, dependent on whether the shipment contains natural or genetically modified pathogens or infectious fluids. These tissues are submitted to particular packaging, labeling, and quantity restrictions as well as documentation requirements.

The protocol followed after occupational exposure to HBV depends on the sensitivity of the exposed worker and the serostatus of the source, and requires that prophylaxis with HBV vaccine, hepatitis B immunoglobulin, or both, be started as soon as possible, ie, within 1-7 days of exposure. In the event of contamination with $\mathrm{HCV}$, follow-up in the absence of prophylaxis depends on whether the patient presents without unfavorable reactions to antiviral therapies, during the acute phase.

In cases of HIV exposure, antiretroviral prophylaxis is required, and it is necessary to perform the test and to have the data within the first 4 hours from the exposure. ${ }^{21-28}$

At the beginning of the studies about HBV, HCV, and HIV, there has been much discussion about possible modes of transmission, especially as only about half of the described cases of viral exposure have a certain main parenteral view. It has been established that blood-to-blood or blood-to-body fluids in direct contact are important in viral transmission, but the issue regarding duration of the contact is debatable, with many studies producing legally conflicting evidence regarding reimbursements to infected health care workers. ${ }^{29-31}$

The principal aim of the present work was to identify situations of risk for health care workers in a pediatric intensive care environment in the FVG region and to determine whether 
control of biological risk could be improved when testing is subject to external quality assessment (EQA). The second objective was to highlight the need to apply the EU recommendations and appropriate testing procedures to minimize not only the biological risk to health care workers but also the risk of litigation.

\section{Materials and methods}

This analysis looked for differences (using numbers and percentages) before and after education and training courses on how to avoid biological accidents. Incident reports filed by nurses and doctors were categorized according to type of biological accident, ie, blood splash, needle stick injury, or a cut made by a contaminated instrument. The case numbers, type of exposure incidents and their distribution in the health care workers during the years 2012-2013 was studied using Pearson's test (chi-squared test computing with software R). The control of the analytic process of the related tests and the monitoring of an excellent quality standard of execution, were studied using the Levey Jennings chart, which provides information about process capability with histograms and flow tables.

In total, 230 nosocomial risk events occurred in the departments of oncology and pediatric-obstetric surgery and in the intensive care unit at Burlo Garofolo Children's Hospital, Trieste, between January 2012 and December 2013. Biological accidents identified in 158 case reports were investigated, and the relevant tests for aspartate transaminase, immunoglobulin G, HIV, HCV, and HBV carried out by Roche Diagnostics (Meylan, France) were submitted for EQA (Randox Laboratories, Northern Ireland).

The procedures (EU guidelines 2010/32), to apply to all health care workers of the hospital, were approved by the Bioethics Committee of the Maternal and Child Health "Burlo Garofolo" Institute, and then illustrated to the involved personnel with specific courses of formation performed by physicians of the Public Health Prevention Service of the hospital. The course provided information about the procedures to follow by health care workers in the event of accident, including appropriate infection control measures and the way to notify such accidents and their causes. All the personnel had a formal procedure to confirm learning and understanding (Figure 1). During the courses a specific activity of sensitization had been done, in collaboration with representatives of the workers and hospital unions, to confirm the importance of the following themes: the risks associated with contact with blood or organic liquids, the use of sharp cutting devices, the effectiveness of immunization therapy and vaccination (estimate and post exhibition).

Given the relatively high cost of HIV testing, EQA was subdivided according to the diagnostic and analytical methodology used and centralized in the laboratory of a general hospital in Trieste. An internal quality control (IQC) procedure specific for low immunoglobulin $\mathrm{G}$ values was implemented to define the possible natural deficit of immunosuppressed health personnel or nonresponders: the distance from the mean was measured in standard deviation (SD) and then the values were signaled on a diagram: a mean of 2 SD limits was established at both levels (day-to-day performance).

The EQA and IQC controls were performed by Randox Laboratories and plotted on a Levey Jennings chart.

\section{Results}

One hundred and fifty-eight nosocomial risk events were reported by health care workers in 2012, and comprised 55 needle stick injuries (34.81\%), 59 blood splashes (37.34\%), and 44 cuts with infected instruments $(27.84 \%)$. The risk of sustaining a cut was related to movement error during surgery when the appropriate procedure was not being followed or when devices were being assembled and passed between doctors and nurses. The high percentage of needle stick injuries (involving 55 physicians [34.81\%] and 41 nurses [25.94\%]) was related to recapping of their use. No health care workers were found to be infected with HCV, HBV, or HIV.

The number of nosocomial risk events decreased to 61 in 2013, and comprised two needle stick injuries (3.27\%), 35 blood splashes $(57.37 \%)$, and 25 cuts with contaminated instruments (40.98\%). The number of subcutaneous abscesses

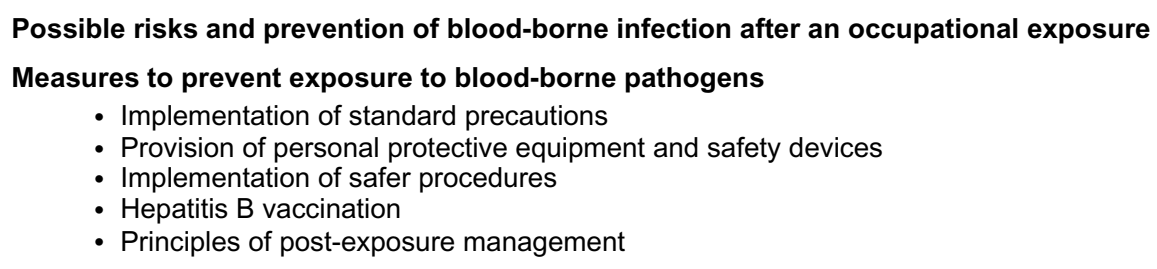

Figure I Educational program. 
Table I Case numbers and type of exposure

\begin{tabular}{llllll}
\hline Year & Cases $(\mathbf{n})$ & Type of exposure & $\mathbf{n , \%}$ & Health workers involved & n, \% \\
\hline 2012 & 158 & Blood splashes & $59(37.34)$ & Physicians & $67(42.40)$ \\
& & *Needle stick injuries & $55(34.8 I)$ & Nurses & $41(25.94)$ \\
& & Cut with contaminated instruments & $44(27.84)$ & Others & $50(31.64)$ \\
2013 & 61 & Blood splashes & $35(57.37)$ & Physicians & $18(29.50)$ \\
& & *Needle stick injuries & $2(03.27)$ & Nurses & $15(24.59)$ \\
& & Cut with contaminated instruments & $25(40.98)$ & Others & $24(39.34)$ \\
Total & 230 & & & \\
\hline
\end{tabular}

Note: $* P<0.05, \chi^{2}$ test.

with scarring resulting from cuts with sharp instruments decreased from three (one of which was the subject of medicolegal proceedings) in 2012 to none in 2013. The frequency distribution of events showed a decrease in all three types of biological accidents (Pearson's test), including a statistically significant decrease in the number of needle stick injuries between 2012 and $2013\left(P<0.05, \chi^{2}\right.$ test; Table 1$)$.

The analytical control for aspartate transaminase demonstrated an improvement on EQA (from 3 to $2 \mathrm{SD}$; Figures 2 and 3). The EQA for HCV, HBV, and HIV and the IQC for immunoglobulin G controls in 2013 were within one SD (Figures 4-6).

In this investigation having a formal procedures for standard care was a factor in determining the knowledge in nurses, as hand hygiene after removal of gloves, and control measures for health care-associated infections (HAIs). Nurses had more attention than physicians about the use of appropriate control measures for HAIs (eg, avoiding needle stick injuries when recapping). It is possible that such differences may be attributed to the preventive activities involving accidents and implicating HAIs. Moreover, the developed training about HAIs influences knowledge and behaviors, so nurses are more prepared than medical doctors to proper HAI

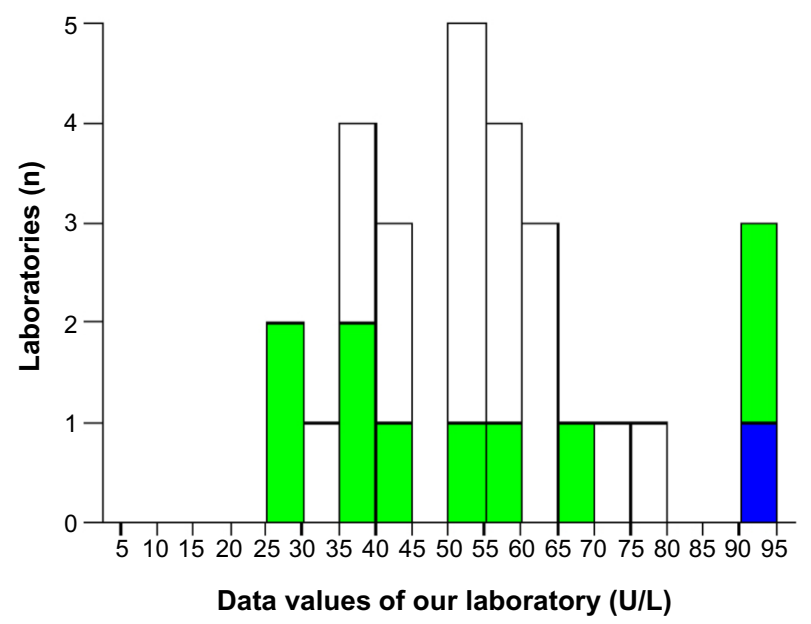

Figure 2 Aspartate transaminase: external quality assessment in 2012. Note: The bold bar indicates the position of the laboratory. control measures, since they have received information from educational courses and scientific journals. This shows that providing health care workers with appropriate information reinforced the understanding, especially in a specific risk group like our study sample.

\section{Discussion}

The present study was limited to a descriptive analysis of events in only one pediatric hospital in the FVG region for the reason that the Institute for Maternal and Child Health is the sole facility with pediatric expertise in this region, with the other health care institutions in the region being general hospitals for adult patients.

It is not possible at this time to extrapolate our findings to other institutions, given the differences in programs, pathologies, and departments, and considering that this is only an initial phase of the Eurosurveillance program in Italy.

At least half of the children admitted to the departments of oncology and pediatric-obstetric surgery, and to the intensive care unit at the Institute for Maternal and Child Health during our study period were immigrants from Eastern and Middle-Eastern Europe (Romania, Ukraine, Bulgaria). The endemicity of HBV, HCV, and HIV infection is influenced

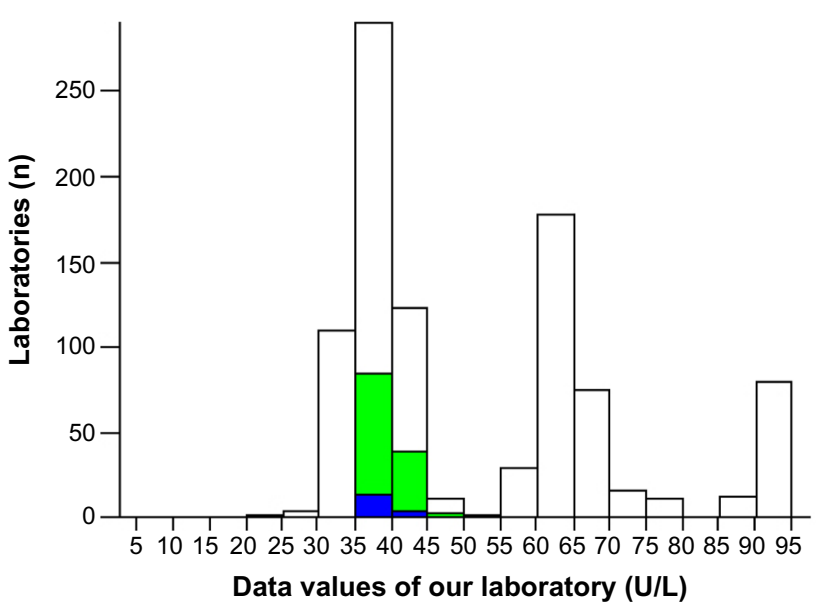

Figure 3 Aspartate transaminase: external quality assessment in 2013. Note: The bold bar indicates the position of the laboratory. 
Acceptable limits derived from biological variation not applicable

Acceptable limits of performance of RIQAs $26.00 \%$

TS and DEV outside limits

Figure 4 Human immunodeficiency virus I-2: external quality assessment in 20I2: valuation is not possible, too few observations.

Abbreviations: RIQAs, report international quality assessment for laboratory medicine; TS, total standard deviation; DEV, standard deviation percentage.

mainly by the age of onset (young or old age). Endemicity of infection is high in some parts of the world, where almost all infections happen during the perinatal period or early in childhood. At least $8 \%$ of the population in these areas is infected, and $70 \%-90 \%$ have serological evidence of previous infection. The risk of HBV infection continues after the first 5 years of life, but its possible contribution to the high rate of chronic infection becomes less important. In countries with an intermediate endemicity of HBV, HCV, and HIV infection (for example, Eastern Europe, the Middle East, and Russia), there are mixed patterns of transmission in infancy, early childhood, and old age. ${ }^{32-35}$

Cuts and puncture wounds involving health care workers exposed to biological fluids are not infrequent in general hospitals, and the risk is even higher in hospitals providing oncology services and other highly complex therapies. Sanitary maneuvers, such as introduction of central catheters, frequent blood sampling, therapeutic injections, injury dressing, and needle sticks, are more frequent in intensive care units and with invasive therapies (eg, stem cell apheresis and autotransplantation) then in general medicine departments. Monitoring of immunosuppressive therapy, and blood and platelet transfusions are often necessary for many months, especially during a pediatric bone marrow transplant in a patient with graft versus host disease. ${ }^{36-39}$

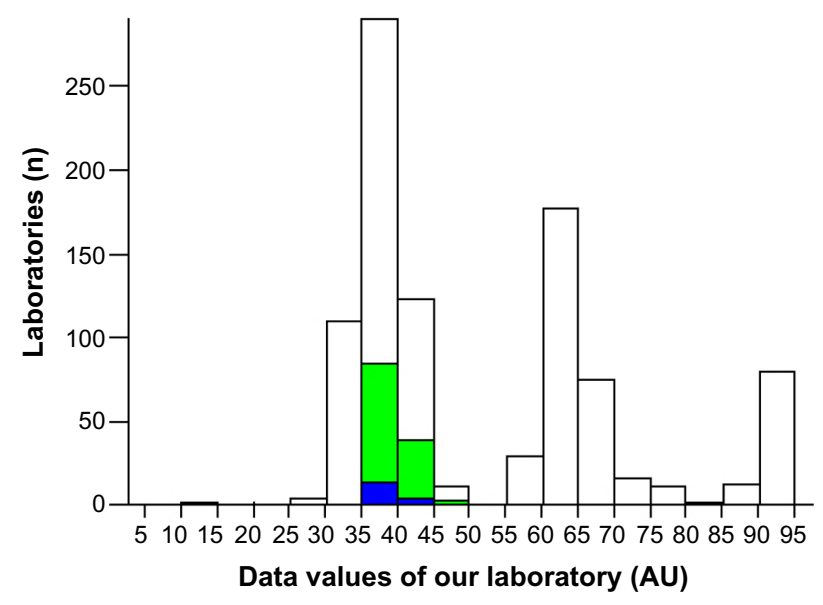

Figure 5 Human immunodeficiency virus I-2: external quality assessment in 2013. Note: The bold bar indicates the position of the our laboratory.

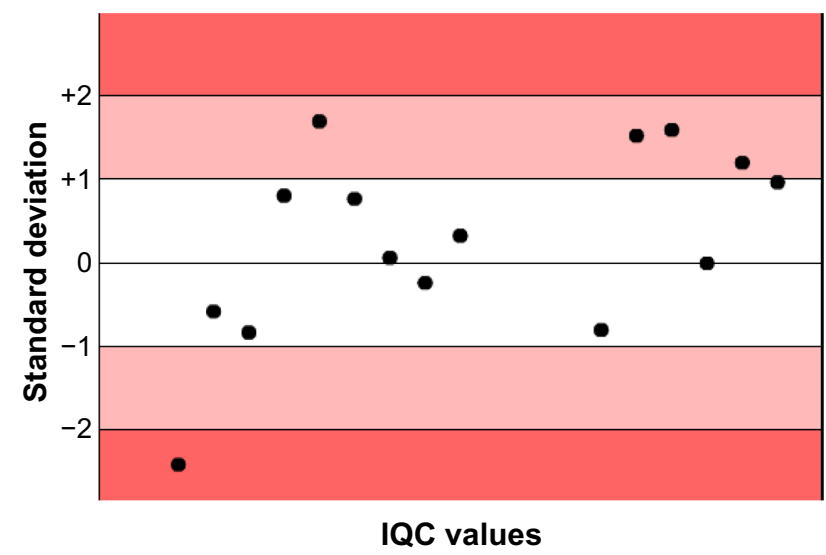

Figure 6 Internal quality control for "low" immunoglobulin G values in 2013. Abbreviation: IQC, internal quality control.

The risk of occupational infection requires introduction not only of adequate procedures but also stringent infection control to minimize the risks to both patients and health care workers. Vaccination and prophylaxis with immunoglobulin $\mathrm{G}$ are important methods for prevention of occupational infection. ${ }^{40} \mathrm{EU}$ laws and regulations play a critical role in the field of public health, from defining the power and jurisdiction of regional health agencies to influencing the social norms that regulate individual behavior. ${ }^{41}$

\section{Conclusion}

Prevention is the primary strategy used to minimize the risk of blood-borne occupational infections. All efforts should be made to reduce the risk of occupational exposure. All hospitals, health organizations, and charitable institutions should have a system readily available to their personnel that includes an educational program, written protocols for rapid reporting, evaluation, counseling, treatment, and follow-up of occupational exposure that places health care workers at risk of acquiring a blood-borne infection.

The secondary strategy, beyond the application of behavioral protocols regarding protection and safety, is better accuracy of test execution and EQA organization, to effectively contribute to the reduction of numbers of medical legal complications, that can often arise contentious, especially when the data analyses have a large standard deviation, with a wide range of values. A systematic quality assessment, a routine control of the pre-exposure vaccination against HBV and of the post-exposure prophylaxis, are urgent. Cost-effectiveness issues must be considered in non-responders to conventional vaccination and prophylactic therapy because they do not produce protective surface antibodies. ${ }^{42}$ The objective of this work is also to emphasize the post-exposure management 
with EQA submitted tests to minimize the responsibilities of the laboratory personnel in possible controversies. The test controls are really always mandatory and the data had to be included in acceptable limits (first or second SD). ${ }^{43,44}$ In Europe the public health system is facing enormous challenges. The laws can help equip the public health system to face these challenges, but only if policymakers undergo a methodical and systematic review about analytic technologies. Guaranteed measures are essential to ensure balanced and effective public health: a multidisciplinary strategy to optimize and capitalize technologies in the laboratory automation.

During this study, health care workers at our pediatric institution showed compliance and high levels of interest with regard to standard precautions. However, the experiences of others highlight an urgent need for implementation of sanitary initiatives to improve health care policies and meet the pressing need for all health care workers in the EU to follow preventive procedures. Governments in EU countries should establish a centralized data base to carefully evaluate whether all EU States are applying the security protocols, and not provide justifications for insufficient data collection and lack of formal procedures.

\section{Disclosure}

The authors report no conflicts of interest in this work.

\section{References}

1. Shanks NJ, A1-Kalai D. Occupation risk of needlestick injuries among health care personnel in Saudi Arabia. J Hosp Infect. 1995;29: 221-226.

2. Rowe PM, Guiffre M. Evaluating needle stick injuries in nursing personnel. AAOHN J. 1991;39:503-507.

3. Porta C, Handelman E, McGovern P. Needlestick injuries among health care workers. A literature review. AAOHN J. 1999;47:237-244.

4. Marziale MH, Nishimura KY, Ferreira MM. [Contamination risks caused by occupational accidents with cutting and piercing material among nursing workers]. Rev Latino Am Enfermagem. 2004;12:36-42. Portuguese.

5. [No authors listed]. Needlestick transmission of HTVL-III from a patient infected in Africa. Lancet. 1984;2:1376-1377.

6. Garner JS. Guideline for isolation precautions in hospitals. Infect Control Hosp Epidemiol. 1996;17:54-80.

7. Centers for Disease Control and Prevention. Update: universal precautions for prevention of transmission of human immunodeficiency virus, hepatitis B virus, and bloodborne pathogens in health-care settings. MMWR Morb Mortal Wkly Rep. 1988;37:377-388.

8. Secretaria do Estado da Saúde. Programa DST/AIDS. [Recommendations and guidelines after exposure in occupational health professionals]. Boletim. 1999;1:22.

9. [No authors listed]. Public Health Service guidelines for the management of health-care worker exposures to HIV and recommendation for post exposure prophylaxis. Centers for Disease Control and Prevention. MMWR Recomm Rep. 1998;47(RR-7):1-33.
10. Hamid SS, Farooqui B, Rizvi Q, Sultana T, Siddiqui AA. Risk of transmission and features of hepatitis $\mathrm{C}$ after needlestick injuries. Infect Control Hosp Epidemiol. 1995;20:63-64.

11. US Public Health Service. Updated US Public Health Service guidelines for the management of occupational exposures to HBV, HCV, and HIV and recommendations for postexposure prophylaxis. MMWR Recomm Rep. 2001;50(RR-11):1-52.

12. Cardo DM, Bell DM. Bloodborne pathogen transmission in healthcare workers. Risks and prevention strategies. Infect Dis Clin North Am. 1997;11:330-346.

13. Monge V, Mato G, Mariano A, Fernández C, Fereres J; GERABTAS Working Group. The Spanish Group Registry of Biological Accidents in Healthcare Workers. Epidemiology of biological-exposure incidents among Spanish healthcare workers. Infect Control Hosp Epidemiol. 2001;22:776-780.

14. Ling ML, Wee M, Chan YH. Sharps and needlestick injuries: the impact of hepatitis B vaccination as an intervention measure. Ann Acad Med Singapore. 2000;29:86-89.

15. Shiao JS, McLaws ML, Huang KY, Guo YL. Sharps injuries among hospital personnel. J Hosp Infect. 2001;49:262-267.

16. Prüss-Üstün A, Rapiti E, Hutin Y. Sharps injuries: global burden of disease from sharps injuries to health-care workers. WHO Environmental Burden of Disease Series, No 3. Geneva, Switzerland: World Health Organization; 2003. Available from: http://www.who.int/ quantifying_ehimpacts/publications/en/sharps.pdf. Accessed April 27, 2005.

17. European Association for the Study of the Liver. Consensus statement (short version). EASL International Consensus Conference on Hepatitis B, Geneva, Switzerland, September 13-14, 2002. J Hepatol. 2003;38:533-540.

18. Puro V, De Carli G, Cicalini S, et al. European recommendations for the management of healthcare workers occupationally exposed to hepatitis B virus and hepatitis C virus. Euro Surveill. 2005;10:260-264.

19. Ippolito G, Puro V, Petrosillo N, De Carli G. Surveillance of occupational exposure to bloodborne pathogens in health care workers: the Italian national programme. Euro Surveill. 1999;4:33-36.

20. Puro V, Cicalini S, De Carli G, Soldani F, Ippolito G. Towards a standard HIV post exposure prophylaxis for healthcare workers in Europe. Euro Surveill. 2004;9:40-43.

21. Rimland D, Parkin WE, Miller GB Jr, Schrack WD. Hepatitis B outbreak traced to an oral surgeon. N Engl J Med. 1977;296:953-958.

22. Henderson DK. Managing occupational risks for hepatitis $C$ transmission in the health care setting. Clin Microbiol Rev. 2003;16: 546-568.

23. [No authors listed]. Recommendations for preventing transmission of infections among chronic hemodialysis patients. MMWR Recomm Rep. 2001;50(RR-5):1-43.

24. Centers for Disease Control and Prevention. Transmission of hepatitis B and $\mathrm{C}$ viruses in outpatient settings: New York, Oklahoma, and Nebraska, 2000-2002. MMWR Morb Mortal Wkly Rep. 2003;52:901-906.

25. Krause G, Trepka MJ, Whisenhunt RS, et al. Nosocomial transmission of hepatitis $\mathrm{C}$ virus associated with the use of multidose saline vials. Infect Control Hosp Epidemiol. 2003;24:122-127.

26. Alter MJ. Healthcare should not be a vehicle for transmission of hepatitis C virus. J Hepatol. 2008;48:2-4.

27. Centers for Disease Control and Prevention. Infection control. Requirements for dialysis facilities and clarification regarding guidance on parenteral medication vials. MMWR Morb Mortal Wkly Rep. 2008;57:875-876.

28. Siegel JD, Rhinehart E, Jackson M, Chiarello L; The Healthcare Infection Control Practices Advisory Committee. Guideline for isolation precautions: preventing transmission of infectious agents in healthcare settings, June 2007. Available from: http://www.cdc.gov/ncidod/dhqp/ gl_isolation.html. Accessed December 31, 2008.

29. Bálint T, Halász S, Lengyel G, Németh E, Fehér J.[HCV infection from the viewpoint of medical law]. Orv Hetil. 2006;147(20):937-943. Hungarian. 
30. Paintsil E, Binka M, Patel A, Lindenbach BD, Heimer R. Hepatitis C Virus Maintains Infectivity for Weeks After Drying on Inanimate Surfaces at Room Temperature: Implications for Risks of Transmission. J Infect Dis. 2014;209(8):1205-1211.

31. Keyvani H, Fazlalipour M, Monavari SH, Mollaie HR. Hepatitis C virus--proteins, diagnosis, treatment and new approaches for vaccine development. Asian Pac J Cancer Prev. 2012;13(12):5931-5949.

32. Karapetyan AF, Sokolovsky YV, Araviyskaya ER, Zvartau EE, Ostrovsky DV, Hagan H. Syphilis among intravenous drug using population: epidemiological situation in St Petersburg, Russia. Int J STD AIDS. 2002;13:618-623.

33. [No authors listed]. Global Surveillance and Control of Hepatitis C. Report of a WHO Consultation Organized in Collaboration with the Viral Hepatitis Prevention Board, Antwerp, Belgium. J Viral Hepat. 1999;6:35-47.

34. Seme K, Poljak M, Begovac J, et al. Low prevalence of hepatitis C virus infection among human immunodeficiency virus type 1-infected individuals from Slovenia and Croatia. Acta Virol. 2002;46:91-94.

35. Rhodes T, Platt L, Maximova S, et al. Prevalence of HIV, hepatitis C and syphilis among injecting drug users in Russia: a multi-city study. Addiction. 2006;101:252-266.

36. Goldman J. Peripheral blood stem cells for allografting. Blood. 1995;85: 1413-1415.
37. Russell N, Gratwohl A, Schmitz N. The place of blood stem cells in allogeneic transplantation. Br J Haematol. 1996;93:747-753.

38. Lane T. Allogeneic marrow reconstitution using peripheral blood stem cells: the dawn of a new era. Transfusion. 1996;36:585-589.

39. Palmović D, Crnjaković-Palmović J. Prevention of hepatitis B virus (HBV) infection in health-care workers after accidental exposure: a comparison of two prophylactic schedules. Infection. 1992;21:42-45.

40. Poland GA. Hepatitis B immunization in health care workers. Dealing with vaccine nonresponse. Am J Prev Med. 1998;16:73-77.

41. Dati F. The new European directive on in vitro diagnostics. Clin Chem Lab Med. 2003;41:1289-1298.

42. Murnane PM, Heffron R, Ronald A, et al. Pre-exposure prophylaxis for HIV-1 prevention does not diminish the pregnancy prevention effectiveness of hormonal contraception. AIDS. 2014;28:1825-1830.

43. Fraser CG, Hyltoft Petersen P, Libeer JC, Ricos C. Proposals for setting generally applicable quality goals solely based on biology. Ann Clin Biochem. 1997;34 Pt 1:8-12.

44. Bais R, Armbruster D, Jansen RT, et al; IFCC Working Group on Allowable Error for Traceable Results (WG-AETR). Defining acceptable limits for the metrological traceability of specific measurands. Clin Chem Lab Med. 2013;51:973-979.
Risk Management and Healthcare Policy

\section{Publish your work in this journal}

Risk Management and Healthcare Policy is an international, peerreviewed, open access journal focusing on all aspects of public health, policy, and preventative measures to promote good health and improve morbidity and mortality in the population. The journal welcomes submitted papers covering original research, basic science, clinical \& epidemio-

\section{Dovepress}

logical studies, reviews and evaluations, guidelines, expert opinion and commentary, case reports and extended reports. The manuscript management system is completely online and includes a very quick and fair peerreview system, which is all easy to use. Visit http://www.dovepress.com/ testimonials.php to read real quotes from published authors. 